\title{
El anarcosindicalismo en Granada durante la II República. (Desde las elecciones de noviembre de 1933 hasta la victoria del Frente Popular)
}

\author{
GONZALO BUTRON PRIDA
}

En el otoño de 1933, tras la ruptura de la coalición republicanosocialista, se disolvieron las Cortes y fueron convocadas nuevas elecciones generales para el próximo 19 de noviembre. Ante esta nueva convocatoria, la postura de la CNT consistió en ordenar a sus seguidores que se abstuvieran de participar en los comicios. De hecho, los anarquistas harían campaña en contra de las elecciones y a favor de la amnistía; su lema "Frente a las urnas, revolución social, recordaba la tarea de alcanzar la revolución social con independencia del resultado que deparara el proceso electoral ${ }^{1}$.

Esta sería la consigna defendida en Granada en el mitin organizado por la CNT en el teatro Cervantes. En él, se sucedieron las intervenciones del obrero anarquista José Zarco, del abogado de los sindicatos Benito Pabón, del también obrero Crespo y del redactor de CNT Avelino González, quienes aconsejaron a los trabajadores que se abstuvieran de acudir a las urnas y que se unieran para hacer la revolución social, completando su discurso con un ataque a la burguesía, al capitalismo y al parlamento, además de a republicanos y socialistas. Su concepcián del abstencionismo quedaba claramente expuesta:

-... la palabra abstención es sinónimo de revolución ... todos los trabajadores deben estar prestos a la lucha dejando de acudir a las urnas donde van a delegar su propia autoridad. ${ }^{2}$.

Hasti: ahora, se ha venido considerando que fue la abstención anarquist: la que, junto a otros factores, permitió el triunfo de la dere-

(1) BRADEMAS, John. Anarcosindicalismo y reublución en España (1930-1937). Barcelona, 1974. p. 108.

(2) El Defensor de Granada. 13 de noviembre de 1933 (edición de tarde). Desde ahora se abreviará El Defensor. 13.XI.1933, especificando con una (t) si se refiere a la edición vespertina. 
cha en las elecciones. Y comoquiera que se había prometido un nuevo levantamiento insurreccional si tal triunfo se producía, el gobierno pudo tomar precauciones con tiempo, de ahí que declarara el estado de emergencia y pudiera practicar numerosas detenciones, al mismo tiempo que clausuraba la mayoría de los centros obreros. Estas medidas redujeron notablemente la capacidad de acción de los sublevados, cuyos levantamientos sólo revistieron cierta importancia en zonas de Aragón y La Rioja ${ }^{3}$.

En Granada, las medidas preventivas permitieron sorprender una reunión clandestina de elementos afiliados a las Juventudes Libertarias, practicándose nueve detenciones in situ y otras dos con posterioridad $\mathrm{d}^{4}$.

Aunque las primeras precauciones fueron redobladas y se establecieron patrullas y puestos de vigilancia estratégicos, en la noche del 9 de diciembre fueron provocados distintos incendios en varios puntos de la ciudad, que afectaron principalmente a conventos e iglesias. Entre ellos, los que revistieron mayor importancia fueron los producidos en el barrio del Albayzín, donde, además, se registraron enfrentamientos armados que requirieron la intervención del ejército y del cuerpo de motoristas vigilantes de la carretera. Los incidentes no pararon ahí, sino que la noche siguiente, fue volado el canal de la fábrica de electricidad de Pinos Genil, lo que produjo un apagón en la ciudad. La mañana del 11, se repartirían manifiestos anarquistas que incitaban a los obreros a la revolución por medio de la huelga general. De hecho, y aunque la UGT llamara a sus afiliados a volver al trabajo, se iniciaría una huelga en la que participaron tranviarios, taxistas, camareros, dependientes, empleados de oficinas y trabajadores de la construccións.

El balance de estas agitadas jornadas arrojaría un saldo de más de sesenta personas detenidas, además de haberse confiscado numeroso material propagandístico, así como explosivos y armas ${ }^{6}$. Cuando se fue restableciendo la normalidad, se reaccionó desde los sectores más conservadores de la ciudad, que pidieron el establecimiento de un cuartel de la guardia civil en el Albayzín, además de abrirse un expediente para lorrar depurar posibles responsabilidades en el cuerpo de bomberos, $\mathrm{d}_{c} \mathrm{da}$ su supuesta pasividad durante el transcurso de los incendios ${ }^{7}$.

Entre tanto, las detenciones siguieron siendo nota común en aquellos días, celebrándose en enero los juicios contra los implicados en el

(3) BRADEMAS; J. op. cit. pp. 113-115.

(4) El Defensor. 5.XII.1933.

(5) El Defensor. 10-13.XIl.1933.

(6) El Defensor. 12-13.XII.1933.

(7) El Defensor. 15, 16 y 30.XII.1933. 
incendio del convento de las Tomasas y en la voladura del salto de agua de la compañía de electricidad ${ }^{8}$.

Este momento de agitación revolucionaria, que cerraba un ciclo iniciado en 1932, a cabó mermando considerablemente la combatividad del movimiento insurreccional, y se vio sucedido por otro de calma que permitió afrontar la idea de levantar un frente obrero único contra el fascismo9, de cuyo ascenso parecían dar prueba actos como la concentración de las JAP en El Escorial, o la amnistía concedida a los implicados en la intentona golpista de carácter monárquico descubierta en 1932.

En el mitin del primero de mayo celebrado en Granada, ya podían verse reflejadas estas tendencias de principios de 1934. En el mitin, en el que también intervinieron Ramón Lamoneda y un representante del Bloque Estudiantil de Ofensiva Revolucionaria, Julián Noguera; portavoz de lós fẹselistas, defendió la idea de formar un frente obrero de lucha contra el fascismo y contra el capitalismo:

-La revolución social es de los sindicalistas, comunistas, anarquistas y socialistas, y todos debemos poner nuestras manos en el corazón, para que con la unión de todos ir a la pulverización del capitalismo ... No es el momento de separarse ... que ninguna organización obrera niegue su colaboración. Hay que ponerse en contacto y dar cima a la obra para, en la calle, y en sus guaridas, acabar con el fascio ${ }^{10}$.

No obstante, esta postura de la FSL, no fue compartida por la CNT, que no estuvo presente en el mitin, en el que se leyó un comunicado de la Federación de Sindicatos Unicos de Granada que precisamente achacaba la incomparecencia cenetista a la presencia de la FSL ${ }^{11}$.

Finalmente, la entrada en el gobierno de miembros de la CEDA, que pareció coni" mar el temor al creciente ascenso del fascismo, fue contestada con un levañtamiento que tuvo lugar durante el otoño de 1934, pero que sólo contó con una acción obrera conjunta en Asturias, inhibiéndose la CNT de participar en una lucha de motivación política ${ }^{12}$.

Estos meses fueron bastante movidos en Granada. La noche del 20 de septiembre fue sorprendida una reunión clandestina de anarcosindicalistas, donde fueron detenidas 24 personas, identificadas

(8) El Deferisor. 15 y 17.I.1934. En el caso del incendio, fueron tres los condenados, con unas penas que oscilaron entre los 4 meses y los 19 años de prisión. En cuanto al del salto de agua, tres de los procesados fueron condenados a 23 años de reclusión mayor, mientras que otros cinco fueron absueltos.

(9) ELORZA, Antonio. La utopia anarquissa bajo la Segunda Repüblica española. Madrid, 1973. pp. 462-463.

(10) El Defensor. 3.V.1934.

(11) Ibidern.

(12) BRADEMAS, J. op. cit. p. 142. 
posteriormente como anarcosindicalistas (diez), sindicalistas (cinco), jóvenes libertarios (cuatro), anarquistas (dos) y comunistas libertarios (uno). Estas detenciones dieron luego pie a que se practicaran otras durante los días siguientes, para más tarde incrementarse el número de detenidos con motivo de la explosión de un petardo en el palacio Müller de la Gran Vía, incidente que además provocó que de nuevo se clausuraran la Casa del Pueblo y los centros obreros ${ }^{13}$.

Los sucesos de estos días llevarían, en definitiva, a que se extremaran las precauciones policiales: custodia por la fuerza pública de las calles céntricas y de los centros oficiales, registros domiciliarios, nuevas detenciones, etc.; para, el 7 de octubre, establecerse, como en el resto de Espạna, el estado de guerra y la ley de marcial. En los días siguientes, la prensa, visiblemente intervenida, no ofrecería una información clara sobre los acontecimientos que habían sucedido, aún así, siguió hablando de numerosas detenciones y de algunos tiroteos, así como de las víctimas de la fuerza pública, que más tarde serían homenajeadas ${ }^{14}$.

Las medidas preventivas, que en Granada también incluyeron una reorganización policial y un mayor control de pensiones y hoteles, se articularon a nivel nacional con la prorrogación del estado de guerra y de la censura previa en la prensa ${ }^{15}$.

Sería precisamente el mantenimiento del sistema de vigilancia pública en un nivel tan intenso el que permitiría descubrir nuevos complots anarcosindicalistas en Granada en febrero y marzo de 1935, lo que llevó a que se practicaran nuevas detenciones y a que se incautara, además de abundante documentación y propaganda de la CNT y de la FAI, armamento y material explosivo ${ }^{16}$.

La política de persecución y represión obrera abrió paso a una etapa de reorganización que supuso un abandono momentáneo de la vía revolucionaria, para primarse, en cambio, la lucha por la amnistía y por el reconocimiento de los derechos más elementales de los trabajadores. Esta fue, en efecto, la orientación que marcó la exposición que la CNT dirigió en abril al gobierno, que contenía las siguientes reivindicaciones:

. la reapertura de sus locales.

. el levantamiento del estado de guerra.

. la intervención del gobierno para que cesaran los malos tratos en cárceles y comisarías, así como la liberación inmediata de los presos gubernativos.

(13) El Defensor. 21, $24(\mathrm{t})$ y $25 . \mathrm{IX} .1934$ y 2-3.X.1934.

(14) El Defensor. 4, 7, 10, 11, 13, 16-19 y 28.X.1934.

(15) El Defensor. 3.XII.1934 (t) y 3.I.1935.

(16) El Defensor. 6, 6 y 8.II.1935 y 15-16.III.1935. 
. la no aprobación de una nueva ley de asociaciones y de imprenta sin que fuera oída la opinión cenetista.

. el reconocimiento de la labor de los comités pro-presos ${ }^{17}$.

Sin embargo, y a pesar de que cierto aperturismo mostrado desde el gobierno civil granadino había permitido la reapertura de la Casa del Pueblo y la celebración de un mitin de afirmación proletaria, organizado por la Federación Provincial de Agrupaciones Socialistas ${ }^{18}$, no se renunció a la acción directa. Efectivamente, se volvió a la vigilancia y a la represión cuando en septiembre corrieron de nuevo rumores sobre otro complot extremista en Granada. En principio, estos rumores condujeron al gobernador a amenazar con hacer cumplir con rigurosidad la ley de Orden Público y a reprimir cualquier movimiento con toda energía

-... que siempre el gobernador considerará tibia, cuando del castigo depende la tranquilidad y el sosiego de toda la provincia ... Ahora la máxima vigilancia, si llega el caso, la máxima energía. ${ }^{19}$.

Las precauciones tomadas, dieron como resultado el descubrimiento de un intento de atentado en el lugar que estaba preparado para la celebración de la ceremonia de entrega de la bandera de la Guardia Civil, donde se encontraron dos bombas, procediéndose a la inmediata detención de los autores ${ }^{20}$.

El inicio de un proceso de transición hacia una situación más normalizada estuvo marcado, a nivel local, por el fin del estado de prevención y de la censura previa ${ }^{21} \mathrm{y}$, a nivel nacional, por la crisis gubernamental, la disolución de las Cortes y la convocatoria de nuevas elecciones. Coincidiendo con el restablecimiento de la legalidad constitucional, la CNT pidió la reapertura de sus locales. Pero, no obstante el talante abierto del nuevo gobernador Torres Romero -que a su llegada a Granada se autodefinió como republicano fervoroso e independiente-, los centros cenetistas aún continuaban cerrados en enero de $1936^{22}$.

Una vez iniciada la campaña electoral, otra vez se empezó a especular sobre la posible participación de la CNT en las elecciones, y desde el recién creado Frente Popular se le instó a abandonar su secular práctica abstencionista. Largo Caballero así lo expuso en un mitin celebrado en Madrid:

-Si directa o indirectamente la CNT no toma parte en estas elecciones, habrá dejado de prestar a la clase obrera un gran servicio ... ellos tendrán

(17) El Defensor. 6.IV.1935. La prensa publicó una nota resumen.

(18) El Defensor. 11.V.1935, 1.VI.1935 y 3 y 9 (t).IX.1935. En cambio, un mitin pro-amnistía había sido suspendido meses antes (28.VI.1935 y 5.VII.1935).

(19) El Defensor. 19.IX.1935.

(20) El Defensor. 7 ( $\mathrm{t}$ ) y 8.X.1935.

(21) El Defensor. 14.XI.1935 y 7.XII.1935.

(22) El Defensor. 20 y 24.XII.1935 y 8 (t) y 11.I.1936. 
la culpa si el proletariado no puede triunfar contra la reacción ... En este momento la CNT esta obliga da a venir a nuestro lado. El triunfo electoral de ahora no será sólo beneficiosos para el socialismo, ni para el anarquismo, ni para el comunismo ... sino en beneficio de la clase obrera. ${ }^{23}$.

Aunque finalmente la CNT no llegaría a firmar el pacto electoral del Frente Popular, por esta vez, no hizo campaña abstencionista, sino que en sus mitines se ocupó de protestar contra el ascenso del fascismo, contra la pena de muerte y las medidas de seguridad, y a favor de la amnistía ${ }^{24}$. En cambio, el partido Sindicalista, dirigido en Granada por José Alcántara -su presidente- y Antonio Salazar, si que se integraría en el Frente Popular.

Una vez ganadas las elecciones, dos asuntos centraron las preocupaciones de los sectores obreros granadinos: la liberación de los presos políticos y sociales, y la anulación de las actas electorales que habían dado la victoria a la derecha en la provincia de Granada, única provincia andaluza donde el Frente Popular no había ganado.

La primera muestra de solidaridad con los presos fue el homenaje que el 20 de febrero les organizó el comité electoral femenino, al que acudieron varios miles de personas. Cuando el día siguiente el gobernador accidental, López Monís, anunció que se había dado la orden de poner en libertad a los presos políticos de la prisión de Granada, que allí se encontraban desde octubre de 1934 en múmero de 58, los gestos solidarios se repitieron y, de este modo, los obreros del Albayzín y El Fargue organizaron suscripciones a su favor ${ }^{25}$.

Mayor conmoción causó el acto de bienvenida organizado a los presos que llegaban desde prisiones de otras provincias. El 23 de febrero, varios miles de obreros con banderas de la CNT, de las Juventudes Socialistas y del Partido Comunista, además del gobernador civil y de una representación de Izquierda Republicana, acudieron a la estación a recibir a cuatro jóvenes presos llegados desde Cartagena. Acto seguido, se organizó una manifestación hacia la sede del gobierno civil, desde donde representantes cenetistas, socialistas y comunistas, así como el propio gobernador, se dirigieron a los asistentes ${ }^{26}$.

Con respecto a la campaña por la nulidad de las actas, ésta se inició nada más conocerse los resultados de las elecciones, que daban a la derecha como ganadora en la provincia, lo que fue achacado a la intervención de monterillas y caciques. Como acto principal de esta protesta, se dispuso la celebración de un mitin para el domingo 8 de marzo, que fue

(23) El Defensor. 14.I.1936.

(24) BRADEMAS, J. op. cit. p. 163.

(25) El Defensor. 21-23.II.1936 y 8.III.1936.

(26) El Defensor. 25.II.1936. 
convocado por Unión Republicana y los partidos Sindicalista, Comunista y Socialista. La celebración del mitin, al que se calculó que asistieron unas cien mil personas procedentes de toda la provincia, provocó la reacción violenta de las fuerzas de la extrema derecha granadina, a la que la izquierda respondió con el incendio de viviendas de diversos personajes conocidos por su vinculación con la extrema derecha, así como de conventos y de centros religiosos. La ola incendiaria afectaría también a la sede de la Falange, al teatro Isabel la Católica, a los cafés Colón y Royal y al edificio del periódico Ideal ${ }^{27}$. Los incidentes continuarian aún durante unos días más puesto que, como consecuencia de los mismos, se declararía finalmente una huelga general para el día 10, que desembocó en una accidentada jornada en la que se produjeron varias muertes ${ }^{23}$.

Restablecida la calma, se procedió a la detención de numerosos fascistas y monarquizantes, y al homenaje, organizado por el ayuntamiento, de los obreros muertos, cuyo entierro constituyó una importante manifestación de sentimiento a la que se calculó que asistieron más de cuarenta mil personas: la marcha la abría una sección de la guardia municipal montada, a la que seguía una presidencia de mujeres que marchaba bajo la bandera de la CNT y de la AIT, tras la que continuaban coronas de la CNT y de.la UGT, los familiares de las víctimas, etc. ${ }^{29}$.

Finalmente, las actas serían anuladas y, tras la celebración el 3 de mayo de nuevas elecciones, el Frente Popular conseguiría los trece escaños que correspondían a Granada ${ }^{30}$.

\section{RECAPITULACION}

Utilizando como fuente el periódico El Defensor de Granada, se ha intentado seguir y analizar el comportamiento de los anarquistas granadinos entre noviembre de 1933 y marzo de 1936, período durante el que se constata una evolución marcada por la existencia de un compromiso de lucha que, en unas ocasiones, se manifestó a través de la acción directa como medio de alcanzar la ansiada revolución social-, mientras que en

(27) El Defensor. 4.III.1936 (convocatoria del mitin). En la Hemeroteca de la Casa de los Tiros faltan los ejemplares de $E l$ Defensor correspondientes a los días 9 , 10 y 11 de marzo. No obstante, Rafael GIL BRACERO recoge los sucesos de aquellos días en .Los precedentes de una guerra: la primavera de 1936 en Granada. en La Guerra Civil en Andalucia Oriental 1936-1939. Granada, 1987. pp. 51-57.

(28) RUIZ MANJON-CABEZA, Octavio. -Almería, Jaén y Granada en vísperas de la Guerra Civil. (Desde las elecciones de febrero hasta la sublevación de julio). en La Guerra Civil .... pp. 13-14.

(29) El Defensor. 13-14.III.1936.

(30) GIL BRACERO, R. art. cit. pp. 57-60. 
otras, se encauzó hacia la consecución y reconocimiento de los derechos más elementales de los trabajadores.

Entre los anarcosindicalistas granadinos, cuya militancia se ha calculado que osciló durante este período entre los 15.000 y los 25.000 afiliados $^{31}$, se formó un grupo activo fuertemente comprometido con la idea de la necesidad de un levantamiento revolucionario. Esta grupo, integrado en su mayor parte por jóvenes libertarios de inspiración faísta, se caracterizó por seguir una política de acción directa e individualista, que contrastó con la orientación más moderada que adoptaron los feselistas de Julián Noguera y los sindicalistas de José Alcántara, que, por el contrario, optaron por la aceptación del juego político y el abandono del compromiso anarquista de la no participación en un régimen republicano que, en opinión de los más puristas, adolecía de una clara vocación burguesa.

Con todo, ambas tendencias coincidirían en cuanto a la comprensión de la conveniencia de mantener la lucha contra el ascenso del fascismo y a favor de la amnistía de los presos sociales y políticos y de la preservación de las libertades públicas. Además, tanto unos como otros tuvieron que enfrentarse a un sistema de vigilancia pública que, ejercido en este período de forma casi continuada, contempló, en los momentos más críticos, la declaración sucesiva de los estados de prevención, alarma y guerra, lo que facilitó la persecución y encarcelamiento de los obreros, así como la clausura de sus centros sociales.

(31) GIL BRACERO, Rafael. .Las fuerzas políticas en la Granada de 1936. (Las elecciones del 16 de febrero). en La Guerra Civil ... p. 32. De ellos, unos dos tercios corresponderían a la capital. 